\title{
Amyloid Arthropathy Resembling Seronegative Rheumatoid Arthritis in a Patient with IgD-kappa Multiple Myeloma
}

\author{
Masumi FujISHIMA, Atsushi KomatsudA, Hirokazu ImAI, Hideki WaKUI, \\ Wataru WATANABE* and Ken-ichi SAWADA
}

\begin{abstract}
A 67-year-old woman suffered from symmetrical polyarthralgia and multiple joint swelling simulating rheumatoid arthritis (RA). Laboratory examination showed negative results for rheumatoid factor, decreased levels of IgG, IgA, and IgM, and an increased level of IgD. Immunoelectrophoresis in her serum and urine revealed an IgD-kappa monoclonal component and Bence Jones protein (kappa), respectively. A bone marrow biopsy showed an excess of atypical plasma cells. A synovial biopsy revealed amyloid deposition composed of IgDkappa. She was diagnosed with amyloid arthropathy (AmyA) secondary to IgD-kappa multiple myeloma. It is important to pay attention to AmyA due to multiple myeloma in patients with seronegative RA.

(Internal Medicine 42: 121-124, 2003)
\end{abstract}

Key words: amyloid arthropathy, IgD-kappa myeloma, seronegative RA, shoulder pad sign

\section{Introduction}

Polyarthritis occurs in patients with not only rheumatoid arthritis (RA), but also other collagen diseases. On the other hand, systemic amyloidosis is an important complication of multiple myeloma (MM) (1). Amyloid can deposit in many organs including the gastrointestinal tract, heart, liver, kidney and skin, but synovial deposition of amyloid is not well recognized $(1,2)$. Extensive amyloid infiltration in the joints causes polyarthropathy termed amyloid arthropathy (AmyA), and this clinical picture mimics the findings of RA (1-9).

Many cases of AmyA associated with MM have been reported (1, 3-9). However, an extensive review of the literature revealed that there are only two reports of amyloid arthropathy due to immunoglobulin D (IgD)-lambda MM (7, 8). Here, we report the first case with amyloid arthropathy complicated by IgD-kappa MM.

\section{Case Report}

A 67-year-old Japanese woman was admitted to Akita University Hospital on October 19, 2001, because of severe polyarthralgia and bilateral leg edema. From May 2001, she had suffered from polyarthralgia and symmetrical swelling of multiple joints, and had visited a local doctor. She was diagnosed with RA according to the 1987 revised criteria for the classification of RA (10). She had been treated with prednisolone $(5 \mathrm{mg} /$ day $)$ and salazosulfapyridine $(1 \mathrm{~g} /$ day $)$. However, the symptoms were worsening progressively. The patient noticed bilateral leg edema in September, and proteinuria appeared. She was referred to our department for further evaluation.

On admission, she could not stand up and walk by herself because of severe polyarthralgia with a decreased range of motion. Her body temperature was $36.5^{\circ} \mathrm{C}$; pulse rate, 72 beats/min; respiratory rate, 14 breaths/min; and blood pressure, 136/60 mm Hg. A physical examination showed symmetrical enlargement of multiple joints, especially shoulders (Fig. 1) and knees. Joint tenderness and inflammation were mild. Pale conjunctiva and moderate pitting edema in both legs were observed. Macroglossia was not observed. A grade II systolic heart murmur was present at the apex. There was no hepatosplenomegaly or abdominal mass. Results of the lungs and neurological examination were normal.

Erythrocyte sedimentation rate was $88 \mathrm{~mm} / \mathrm{h}$, and CRP was $0.4 \mathrm{mg} / \mathrm{dl}$. The leukocyte count was $4,600 / \mu \mathrm{l}$ (neutrophils $79 \%$, monocytes $7 \%$, lymphocytes $13 \%$, metamyelocytes $1 \%$ ), erythrocyte count $250 \times 10^{4} / \mu \mathrm{l}$, hemoglobin $9.0 \mathrm{~g} / \mathrm{dl}$, hematocrit $26.3 \%$, and platelet count $20.3 \times 10^{4} / \mu 1$. The total urinary protein for 24 hours was $0.5 \mathrm{~g}$. The serum total protein was $7.3 \mathrm{~g} / \mathrm{dl}$, albumin $4.1 \mathrm{~g} / \mathrm{dl}$, blood urea nitrogen 22

From the Third Department of Internal Medicine, *Department of Orthopedics, Akita University School of Medicine, Akita

Received for publication June 20, 2002; Accepted for publication November 15, 2002

Reprint requests should be addressed to Dr. Atsushi Komatsuda, the Third Department of Internal Medicine, Akita University School of Medicine, 1-1-1 Hondo, Akita 010-8543 


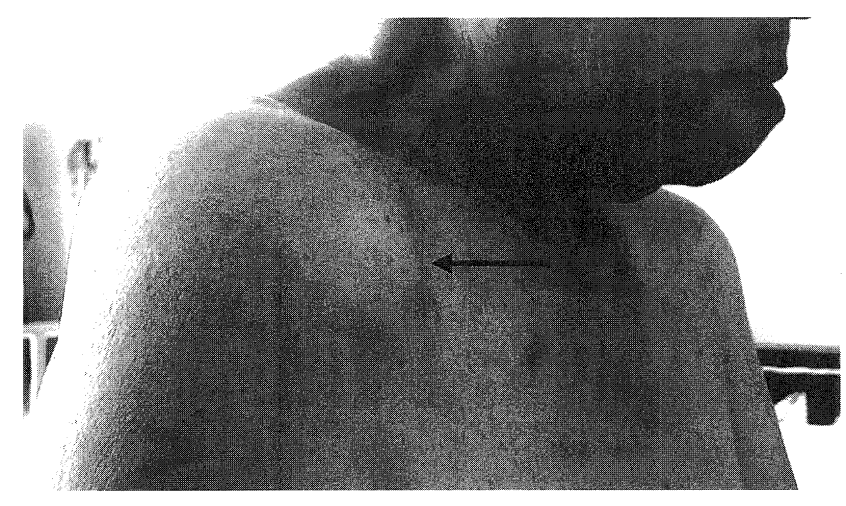

Figure 1. Massive swelling of the right shoulder presenting as the "shoulder-pad sign" (arrow).

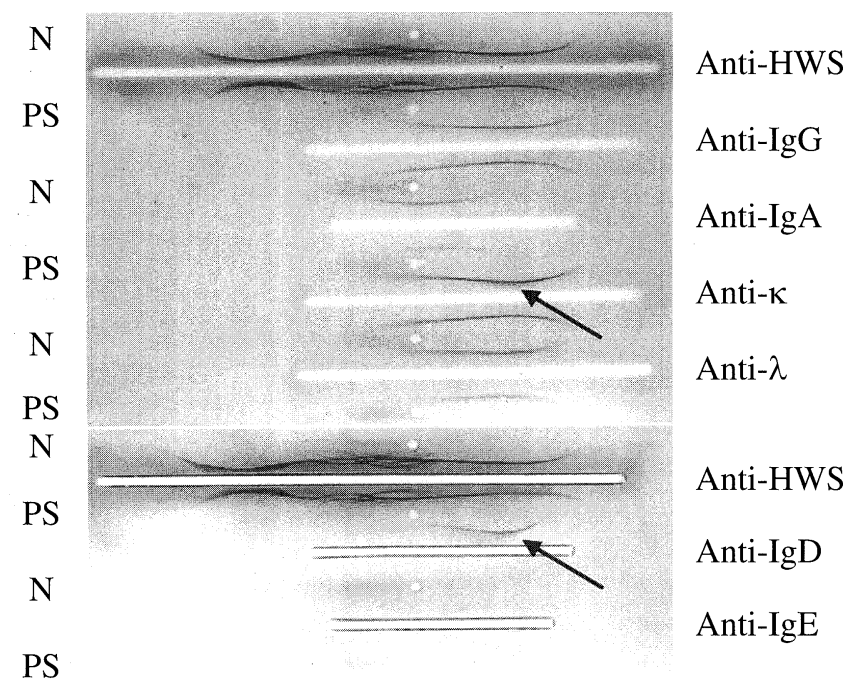

Figure 2. Serum immunoelectrophoretic analysis shows significant monoclonal increase in IgD with increased kappa immunoglobulin light chain (arrows).

$\mathrm{mg} / \mathrm{dl}$, and serum creatinine $0.7 \mathrm{mg} / \mathrm{dl}$. Serum electrophoresis was normal without M-peak. Liver and thyroid function tests were normal. The level of serum calcium was 11.2 $\mathrm{mg} / \mathrm{dl}$, and levels of sodium, potassium, and chloride were normal. Serum IgG was $697 \mathrm{mg} / \mathrm{dl}$, IgA $68 \mathrm{mg} / \mathrm{dl}$, IgM 21 $\mathrm{mg} / \mathrm{d}$, and $\operatorname{IgD} 1,880 \mathrm{mg} / \mathrm{dl}$. The rheumatoid factor, ANA, and cryoglobulins were negative. Serum complements were normal. Serum $\beta 2$-microglobulin was $6.4 \mathrm{mg} / \mathrm{dl}$. Immunoelectrophoresis in her serum and urine demonstrated IgDkappa monoclonal component and Bence Jones protein (kappa type), respectively (Fig. 2). Radiographs of bilateral hands disclosed osteopenia at the left wrist, carpal, and metacarpophalangeal (MP) joints, and the right MP joints. Osteoarthritic changes such as osteophyte were observed in the left thumb interphalangeal, and left and right proximal and distal interphalangeal joints (Fig. 3). Skeletal and both

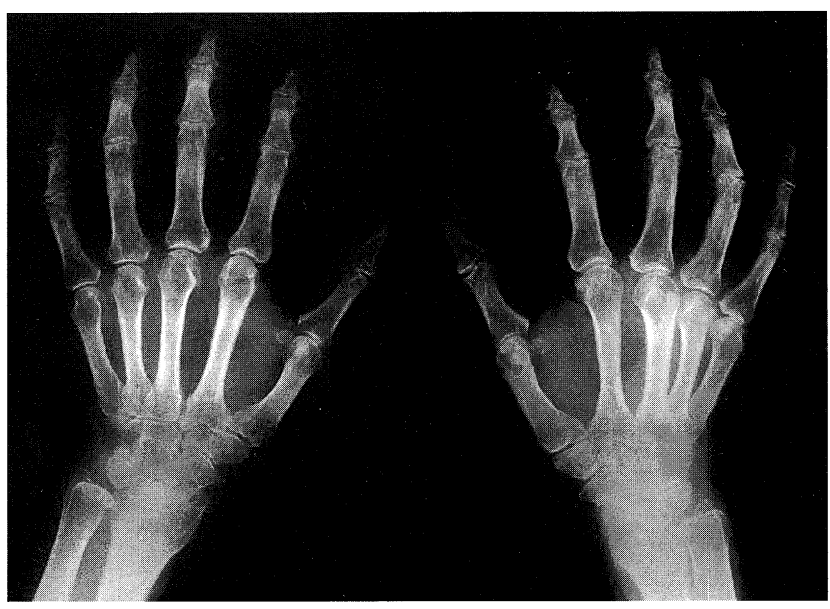

Figure 3. Radiograph of hands shows osteopenia and osteoarthritic deformity.

humeral X-ray films revealed several osteolytic lesions.

A bone marrow biopsy showed an excess of atypical plasma cells (37.6\%) and homogenous deposits. An immunohistochemical examination showed that the pathologic cells and deposits were positive for $\operatorname{IgD}$ and kappa immunoglobulin light chain. The deposits were also positive for Congo red staining (Fig. 4A, B, C, and D). A percutaneous synovial biopsy showed IgD-kappa-related amyloid deposits, confirmed by Congo red staining and immunohistochemistry (Fig. 5A, B and C). Examination of the synovial biopsy with potassium permanganate provided little loss of Congo red affinity.

From these findings, we finally diagnosed the patient with AmyA due to IgD-kappa MM (stage III). Chemotherapy (melphalan, $8 \mathrm{mg} / \mathrm{d}$ for 4 days; prednisolone, $80 \mathrm{mg} / \mathrm{d}$ for 4 days, once a month) was begun. The level of $\operatorname{IgD}$ decreased to less than $100 \mathrm{mg} / \mathrm{dl}$, and polyarthralgia and enlargement of multiple joints gradually improved.

\section{Discussion}

It is well known that amyloidosis is associated with MM. Amyloidosis is present in 6 to $15 \%$ of patients with MM (6). Amyloid deposits are usually observed in the wall of small blood vessels and the connective tissue of major organs including the gastrointestinal tract, heart, liver, kidney, and skin (9). Amyloid infiltration in joints is rare, and the frequency is less than $5 \%$ of patients with amyloidosis caused by MM (2).

AmyA has been reported in patients with all types of MM $(1,3-9)$. However, to our knowledge, to date there have been only two patients with AmyA associated with IgD MM (7, 8). Serum immunoelectrophoresis in these two patients showed IgD-lambda M component. Since amyloid deposits were observed in joints at autopsy, they were finally diagnosed as AmyA caused by IgD-lambda MM. Therefore, we 


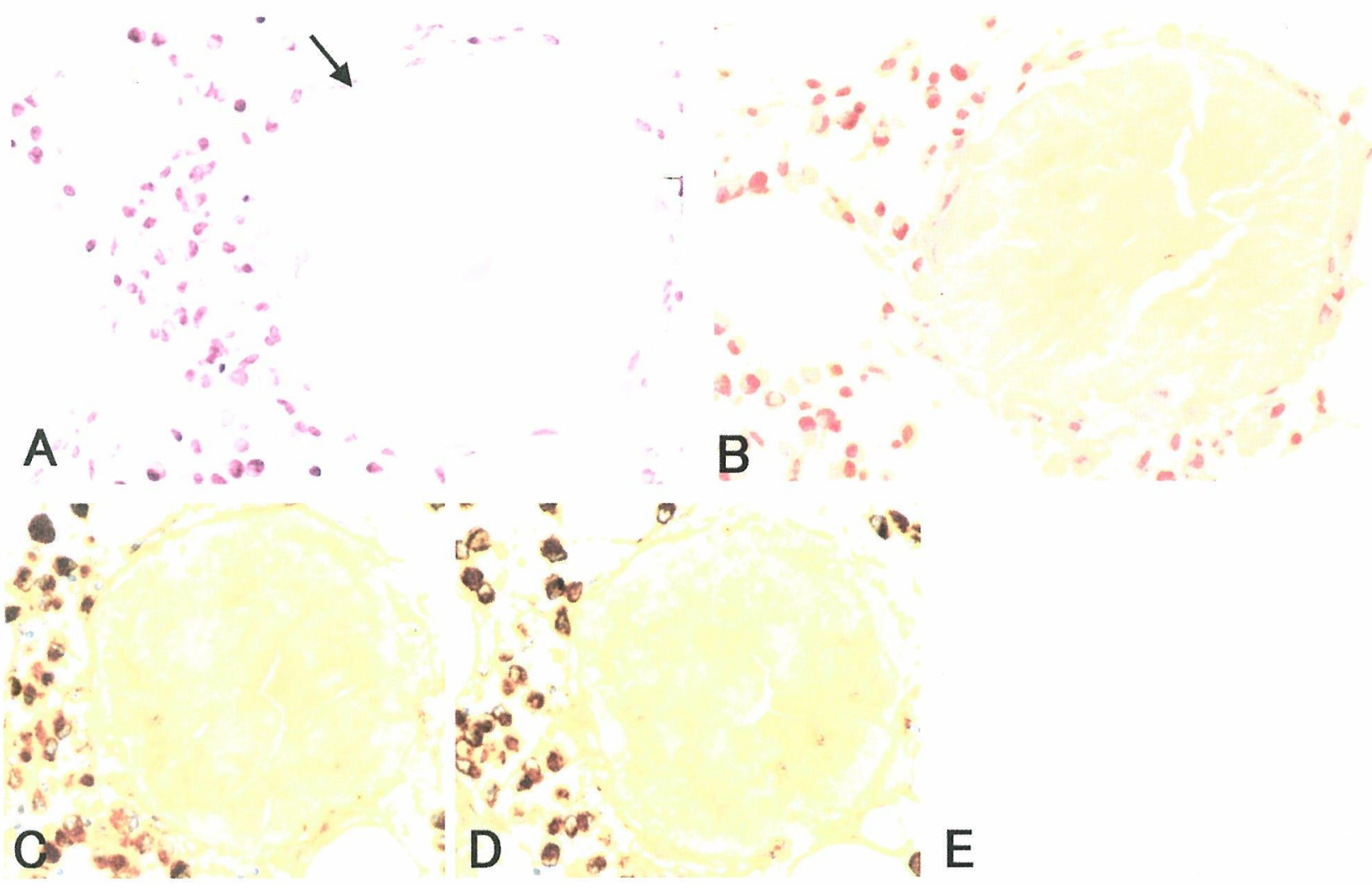

Figure 4. Light microscopic examination of a bone marrow biopsy. A: Increased number of atypical plasma cells and amyloid deposits are seen (arrow) (HE stain, original magnification $\times 400$ ). B: The homogenous deposit was positive for Congo red staining. C: Immunohistochemical study shows that plasma cells and amyloid deposits were positive for IgD. D: Immunohistochemical study reveals that plasma cells and amyloid deposits were positive for kappa immunoglobulin light chain. E: Immunohistochemical study discloses that plasma cells and amyloid deposits were negative for lambda immunoglobulin light chain.

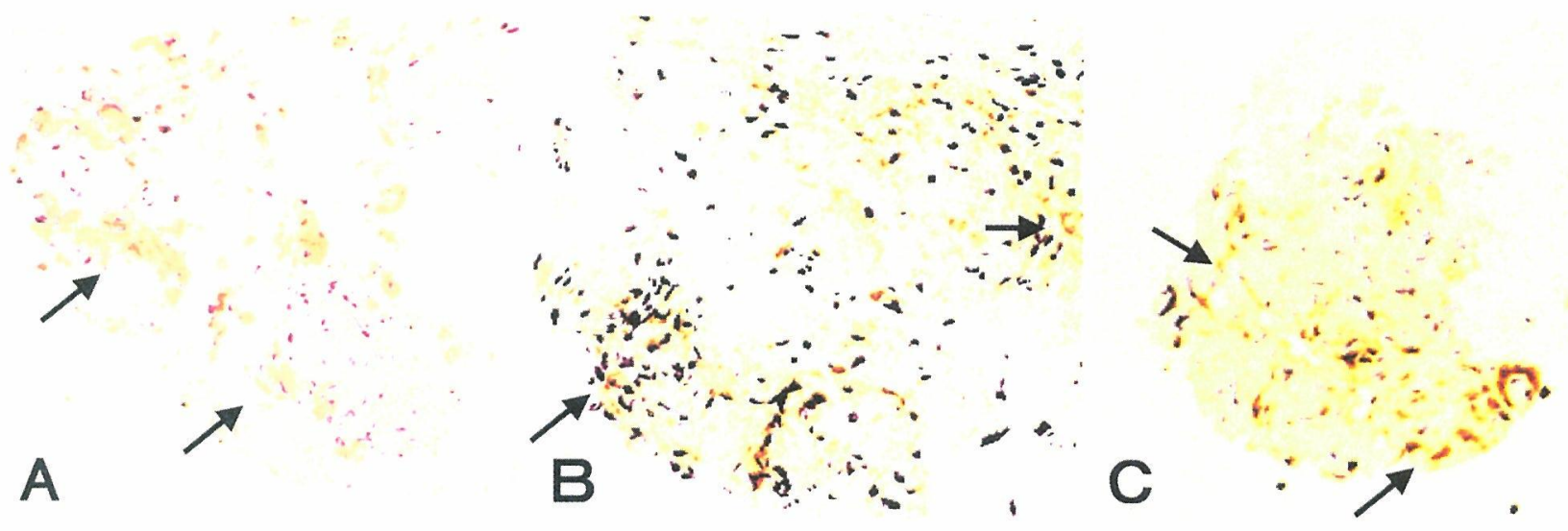

Figure 5. Light microscopic examination of a synovial biopsy taken from the right knee joint. A: Patchy amyloid deposits are seen (arrows) (Congo red staining, $\times 400$ ). B: Immunohistochemical study shows that amyloid deposits were positive for IgD. C: Immunohistochemical study reveals that amyloid deposits were positive for kappa immunoglobulin light chain. 


\section{FUJISHIMA et al}

considered that the present patient is the first case of AmyA due to IgD-kappa MM.

Recognition of IgD MM is difficult because of the occasional absence of the discrete monoclonal peak on serum electrophoresis $(7,8)$. However, even patients with IgD MM often have depressed levels of serum $\operatorname{IgG}, \operatorname{IgA}$, and $\operatorname{IgM}$, anemia, and proteinuria (11) as in our patient. When these abnormal findings are observed, an immunoelectrophoretic assay is required to identify $\operatorname{IgD}$ myeloma protein.

AmyA may resemble the features of RA, and may be mistaken for RA, because pain, stiffness, and swelling of symmetrical multiple joints are often observed in patients with AmyA (1-9). The helpful clinical features in differentiating between AmyA and RA are the absence of fever, low ESR, severe limitation of joints movements with relatively mild synovitis, and the presence of other possible organ involvements with amyloidosis. Especially, the presence of extensive enlarged shoulders, known as the "shoulder-pad sign" $(4,5)$ is notable. Katz et al (4) emphasized that this striking clinical sign is important to diagnose AmyA. The present patient also had the "shoulder-pad sign".

Patients with RA are usually treated with nonsteroidal anti-inflammatory drugs, disease-modifying anti-rheumatic drugs, and/or low-dose steroids. The clinical symptoms improve gradually after therapy. However, AmyA may become worse rapidly and progressively in spite of treatment with such drugs. Fortunately, our patient improved symptomatically after the chemotherapy with melphalan and prednisolone. According to the improvement of swelling of multiple joints and moderate edema in both legs in this patient, prednisolone may be effective to decrease interstitial edema around the joints and legs, since the period of the treatment might be too short to diminish amyloid deposits.
Thus, it is important for physicians to recognize the presence of AmyA due to $\mathrm{MM}$ in patients with unspecified polyarthritis and to treat these patients appropriately.

\section{References}

1) Hickling P, Wilkins $M$, Newman GR, et al. A study of amyloid arthropathy in multiple myeloma. Q J Med 50: 417-433, 1981.

2) Skinner M, Anderson JJ, Simms R, et al. Treatment of 100 patients with primary amyloidosis: A randomized trial of melphalan, prednisone, and colchicine versus colchicine only. Am J Med 100: 290298, 1996.

3) Wiernik PH. Amyloid joint disease. Medicine 51: 465-479, 1972.

4) Katz GA, Peter JB, Pearson CM, Adams WS. The shoulder-pad sign: a diagnostic feature of amyloid arthropathy. N Engl J Med 288: 354 355, 1973.

5) Gordon DA, Pruzanski W, Ogryzlo MA, Little HA. Amyloid arthritis simulating rheumatoid disease in five patients with multiple myeloma. Am J Med 55: 142-154, 1973.

6) de Ruiter EA, Ronday HK, Markusse HM. Amyloidosis mimicking rheumatoid arthritis. Clin Rheumatol 17: 409-411, 1998.

7) Friman C, Tornroth $T$, Wegelius O. IgD myeloma associated with multiple extramedullary amyloid-containing tumours and amyloid casts in the renal tubules. Ann Clin Res 2: 161-166, 1970.

8) Nashel DJ, Widerlite LW, Pekin TJ Jr. IgD myeloma with amyloid arthropathy. Am J Med 55: 426-430, 1973.

9) Kurashima C, Hirokawa K, Kato K, et al. Systemic amyloid arthropathy associated with multiple myeloma. Acta Pathol Jpn 37: 853861, 1987.

10) Arnett FC, Edworthy SM, Bloch DA, et al. The American Rheumatism Association 1987 revised criteria for the classification of rheumatoid arthritis. Arthritis Rheum 31: 315-324, 1988.

11) Barlogie B, Shaughnessy J, Munshi N, Epstein J. Plasma cell myeloma, in: Williams Hematology 6th ed, chap 106. Beutler E, Lichtman MA, Coller BS, Kipps TJ, Seligsohn U, Eds. McGraw-Hill, New York, 2001: 1279-1304. 